\title{
Alteration of Cartilage Glycosaminoglycan Protein Acceptor by Somatomedin and Cortisol
}

\author{
B. S. KILGORE, M. L. MCNATT, S. MEADOR, J. A. LEE, E. R. HUGHES, AND M. J. ELDERS ${ }^{(32)}$ \\ Departments of Pediatrics and Biochemistry, University of Arkansas for Medical Sciences, Little Rock, Arkansas and \\ Department of Pediatrics, University of South Alabama Medical College (E.R.H.), Mobile, Alabama, USA
}

\begin{abstract}
Summary
The effect of somatomedin and cortisol on embryonic chick cartilage in vitro indicates that somatomedin stimulates ${ }^{35} \mathrm{SO}_{4}$ uptake while cortisol decreases it with no effect on glycosaminoglycan turnover. Xylosyltransferase activity is increased in crude fractions of somatomedin-treated cartilage but decreased in cortisol-treated cartilage. By using a Smith-degraded proteoglycan as an exogenous acceptor, xylosyltransferase activities from both treatments were equivalent, suggesting that the enzyme was not rate limiting. The results of xylosyltransferase assays conducted by mixing enzyme and endogenous acceptor from control, cortisoltreated, and somatomedin-treated cartilage, suggest both effects to be at the level of the acceptor protein.
\end{abstract}

\section{Speculation}

Glucocorticoids and somatomedin may influence growth in children by regulating the synthesis of the glycosaminoglycan acceptor protein. Present studies suggest that both these hormones alter the synthesis of this protein. Somatomedin increases glycosaminoglycan acceptor protein concentration while cortisol decreases glycosaminoglycan acceptor protein, suggesting that the synthesis of this protein may be an important control mechanism in glycosaminoglycan biosynthesis and subsequent growth. The assumption that the effect is a specific one and that the glucocorticoids and somatomedin act at the same site is speculative at the present time, but provides an attractive hypothesis.

Glucocorticoids and somatomedin influence growth in children. The specific site of action for these two hormones in the regulation of cartilage growth has not been delineated.

The glucocorticoid hormones inhibit epiphyseal cartilage growth and decrease the metabolic activity of cartilage cells (9, 10). The somatomedins, on the other hand, are growth-promoting polypeptides which stimulate epiphyseal cartilage growth and increase the synthesis of a number of functional and structural proteins (6).

The increased rate of skeletal growth following growth hormone administration is paralleled by increased rates of glycosaminoglycan, collagen, and protein biosynthesis in epiphyseal cartilage (6). One easily measured parameter following cartilage stimulation by somatomedin or inhibition by glucocorticoids is radiosulfate uptake into sulfated glycosaminoglycan (16). The sequence of events in glycosaminoglycan biosynthesis has been elucidated in chick cartilage. The reaction sequence involves glycosylation of an acceptor protein and synthesis of a linkage region, followed by the alternating stepwise addition of monosaccharides characteristic of the glycosaminoglycan. Sulfate is incorporated into the sulfated glycosaminoglycans as the chain is synthesized (15).

The first step in the biosynthesis of the major cartilage glycosaminoglycan, chondroitin 4-sulfate, is the synthesis of an acceptor protein followed by the transfer of xylose from UDP-xylose to the protein acceptor by the enzyme xylosyltransferase [UDP-xyloseprotein xylosyltransferase (EC 2.4.2.26)]. Two galactose and one glucuronic acid residues are added in sequence to form the linkage region (11). These reactions require specific glycosyltransferases (Fig. 1).

The level of xylosyltransferase activity in tissue has been shown to be positively correlated with the rate of sulfate incorporation into glycosaminoglycans and, presumably, represents the ratelimiting step in the pathway (19). Chondroitin sulfate biosynthesis is inhibited by inhibitors of protein synthesis (20).

The question is: Does this represent a decrease in endogenous acceptor protein or in the enzyme, xylosyltransferase? $\beta$-Xylosides will initiate chondroitin sulfate synthesis in embryonic cartilage leaflets in the presence of inhibitors of protein synthesis (14). This maneuver bypasses the xylosyltransferase reaction and supports the argument that the concentration of endogenous acceptor protein may be rate limiting in the initiation of chondroitin sulfate synthesis and not the activity of the xylosyltransferase. The glycosyltransferase reactions require two substrates, the UDP sugar and the endogenous acceptor (the second substrate) which is present in the crude preparation along with the enzyme (15). Stoolmiller et al. (19) have shown that xylosyltransferase can be separated from the endogenous acceptor and that a Smith-degraded proteoglycan is a suitable acceptor for xylose in this reaction.

By using these techniques and a Smith-degraded proteoglycan as an artificial acceptor, we have data which suggest that the somatomedins increase glycosaminoglycan biosynthesis by increasing the availability of endogenous protein acceptor, and that glucocorticoids decrease glycosaminoglycan biosynthesis by decreasing the availability of endogenous protein acceptor. These data provide a plausible explanation for the stimulation of glycosaminoglycan biosynthesis and growth by somatomedin as well as the inhibition of glycosaminoglycan biosynthesis and growth by glucocorticoids.

\section{MATERIALS AND METHODS}

\section{CARTILEGE PREPARATION}

Fertile eggs (21) were incubated in a Humidaire egg incubator (22) at $37^{\circ}$, with high humidity, and were rotated hourly. The embryos were killed on day 12 , and the pelvic rudiments and long bone cartilage were removed and incubated for $16 \mathrm{hr}$ in Ham's F10 nutrient mixture (23) containing no serum, $6.4 \%$ serum, or a partially purified plasma factor designated somatomedin, or $1 \mathrm{~mm}$ cortisol phosphate (24). After incubation, the cartilage $(1 \mathrm{~g} / 5 \mathrm{ml})$ was homogenized in $0.2 \mathrm{M}$ sucrose, $0.05 \mathrm{M}$ Tris buffer, $\mathrm{pH} 7.0$, and centrifuged at $10,000 \times g$ for $10 \mathrm{~min}$. The $10,000 \times g$ supernatant fraction containing both "enzyme" and "acceptor" was used for initial assays of the glycosyltransferase activities.

\section{SOMATOMEDIN PREPARATION}

Serum from a single donor containing $66.6 \mathrm{mg}$ protein $/ \mathrm{ml}$ was acidified to $\mathrm{pH} 5.5$ with $\mathrm{HCl}$ and placed in a boiling water bath for $30 \mathrm{~min}$. The resulting supernatant $(30-40 \mathrm{ml} / 100 \mathrm{ml}$ original serum) was pooled, dialyzed at $0^{\circ}$ against distilled water, with 


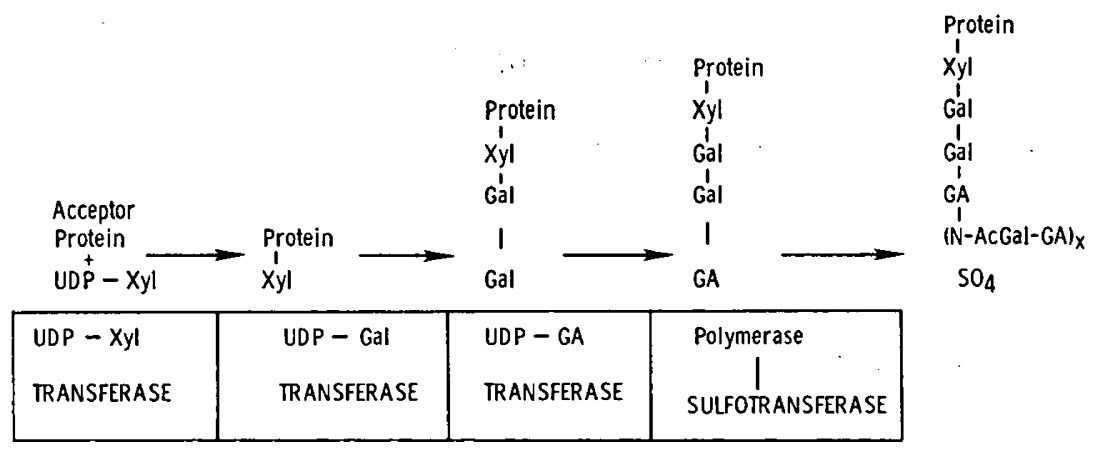

Fig. 1. Schematic representation of the glycosaminoglycan biosynthetic unit.

low-molecular weight dialysis tubing (molecular weight cutoff 3000 ), and lyophilized. The lyophilized material was reconstituted in buffered saline on the day of use. The reconstituted solution contained $4 \mathrm{mg}$ protein $/ \mathrm{ml}$. Boiling decreases the protein content, removes substances that inhibit the bioassay, and releases somatomedin from macromolecular complexes in the serum $(3,8,17)$. The relative activity of the serum before boiling was 1.27 units $/ \mathrm{ml}$ and the activity of the boiled supernatant was 2.11 units $/ \mathrm{ml}$ when compared with a human reference serum in our assay. Thus, boiling resulted in a decrease of the total somatomedin present in the original serum of approximately $50 \%$. This was either destroyed or trapped in the coagulated protein following boiling and centrifugation.

\section{ASSAY OF GLYCOSYLTRANSFERASE}

The glycosyltransferase activities were measured as described by Grebner et al. (7) with minor modifications in our laboratory (5). Xylosyltransferase was assayed at $\mathrm{pH} 6.5$ with $3.2 \mu \mathrm{M}$ UDP $\left.{ }^{14} \mathrm{C}\right]$ xylose $(25)$ and $6 \mathrm{mM} \mathrm{MnCl} 2$ (26). Galactosyltransferase activity was assayed at pH 5.5, using $7.5 \mu \mathrm{M}$ UDP $\left[{ }^{14} \mathrm{C}\right]$ galactose (28) and $4 \mathrm{mM} \mathrm{MnCl}_{2}$. Glucuronyltransferase activity was assayed at pH 6.5 using $4.3 \mu \mathrm{M}$ UDP $\left[{ }^{14} \mathrm{C}\right]$ glucuronic acid (27) and $2 \mathrm{mM}$ $\mathrm{MnCl}_{2}$. One hundred microliters of enzyme preparation were added to the assay. The total reaction volume was $200 \mu \mathrm{l}$ in $0.2 \mathrm{M}$ sucrose, $1.0 \mathrm{mM}$ dithiothreitol, and $50 \mathrm{mM}$ Tris acetate. In studies using exogenous acceptor, xylosyltransferase was assayed as described by Stoolmiller et al. (19) and modified in our laboratory (13) using $250 \mu \mathrm{g}$ exogenous acceptor plus $5 \mathrm{nmole}$ unlabeled UDP-xylose (26). The exogenous acceptor was prepared by Smith degradation of bovine chondroitin sulfate-protein complex as described by Baker et al. $(1,27)$.

Uronic acids were determined by using the carbazole method of Bitter and Muir (2). Protein concentrations were determined according to the method of Lowry et al. (12), using bovine serum albumin as a standard (26). Radioactivity was measured in a liquid scintillation spectrometer using $10 \mathrm{ml}$ Bioflour (30).

For estimation of the half-life of glycosaminoglycans in embryonic chick cartilage, pelvic rudiments were removed and incubated at $37^{\circ}$ in $95 \%$ air $-5 \% \mathrm{CO}_{2}$ for $16 \mathrm{hr}$ in Ham's $\mathrm{F}-10$ nutrient mixture with $5 \mu \mathrm{Ci}$ carrier-free $\mathrm{Na}_{2}{ }^{35} \mathrm{SO}_{4}(30)$. Cartilages were then washed thoroughly with buffered saline and incubated in Ham's F-10 nutrient mixture without ${ }^{35} \mathrm{~S}$, and with or without the somatomedin preparation or $1.0 \mathrm{mM}$ cortisol phosphate. The medium was changed every $48 \mathrm{hr}$. Five rudiments were removed at each time point during the incubation and the radioactivity of the ${ }^{35} \mathrm{~S}$ relative to uronic acid was determined as described by McNatt et al. (13).

\section{RESULTS}

Figure 2 demonstrates that a medium containing $6.5 \%$ of a partially purified serum factor designated somatomedin stimulates ${ }^{35} \mathrm{~S}$ incorporation into chick pelvic rudiments, while a medium containing $1.0 \mathrm{mM}$ cortisol significantly reduces the incorporation of ${ }^{35} \mathrm{~S}$ into uronic acids when compared with cartilage incubated in medium alone. Uptake of ${ }^{35} \mathrm{~S}$ was linear for at least $24 \mathrm{hr}$ in all three groups. Disappearance curves for incorporated ${ }^{35} \mathrm{~S}$ expressed

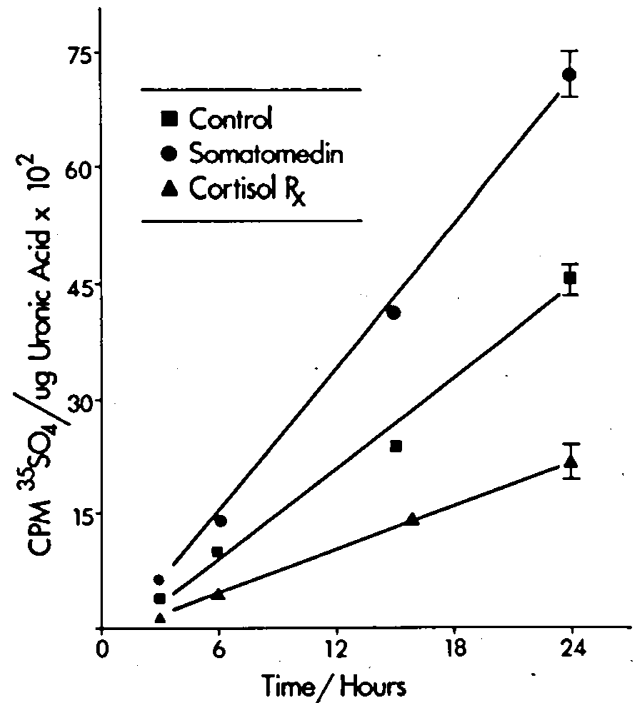

Fig. 2. Radiosulfate uptake by cartilage pelvic rudiments is shown various times during a $24-\mathrm{hr}$ incubation period. The line labeled somatomedin represents data from cartilage incubated in media containing the partially purified serum factor. The control line represents media without additive and the line labeled cortisol represents cartilage incubated in media containing $1 \mathrm{~mm}$ cortisol.

as $\mathrm{cpm} / \mu \mathrm{g}$ uronic acid, following incubation of the cartilage over a 14-day period were also studied and the data are plotted semilogarithmically in Figure 3. The half-times for sulfated glycosaminoglycan in the control (7.8 days) and in somatomedintreated cartilage is 11.9 days as we have previously reported (4).

These data indicate that somatomedin stimulates sulfated glycosaminoglycan biosynthesis rather than decreasing degradation, while cortisol inhibits sulfated glycosaminoglycan biosynthesis. To provide a possible explanation for the somatomedin and glucocorticoid effect on glycosaminoglycan biosynthesis, the activities of the glycosyltransferases involved in the linkage region were determined. The results of assays from six individual experiments on control, somatomedin-, or cortisol-treated cartilage are shown in Table 1 .

Incubation in the presence of the somatomedin preparation significantly increased the activity of UDP xylosyltransferase to $170 \%$ of control value $(P<0.01)$. The activity of UDP galactosyltransferase was $147 \%$ of the control, and UDP glucuronyltransferase $130 \%$. Cortisol, on the other hand, decreased the activity of these enzymes to 65,76 , and $89 \%$ of the control value, respectively.

The apparent changes, shown in Table 1, in the xylosyltransferase activity from the control values could be due to either an alteration in enzyme activity per se or changes in the availability of the endogenous acceptor protein. To study these alternatives, the $10,000 \times g$ supernatant of the cartilage homogenate from control, somatomedin-, and cortisol-treated pelvic rudiments and long bone were partially separated into enzyme and acceptor 


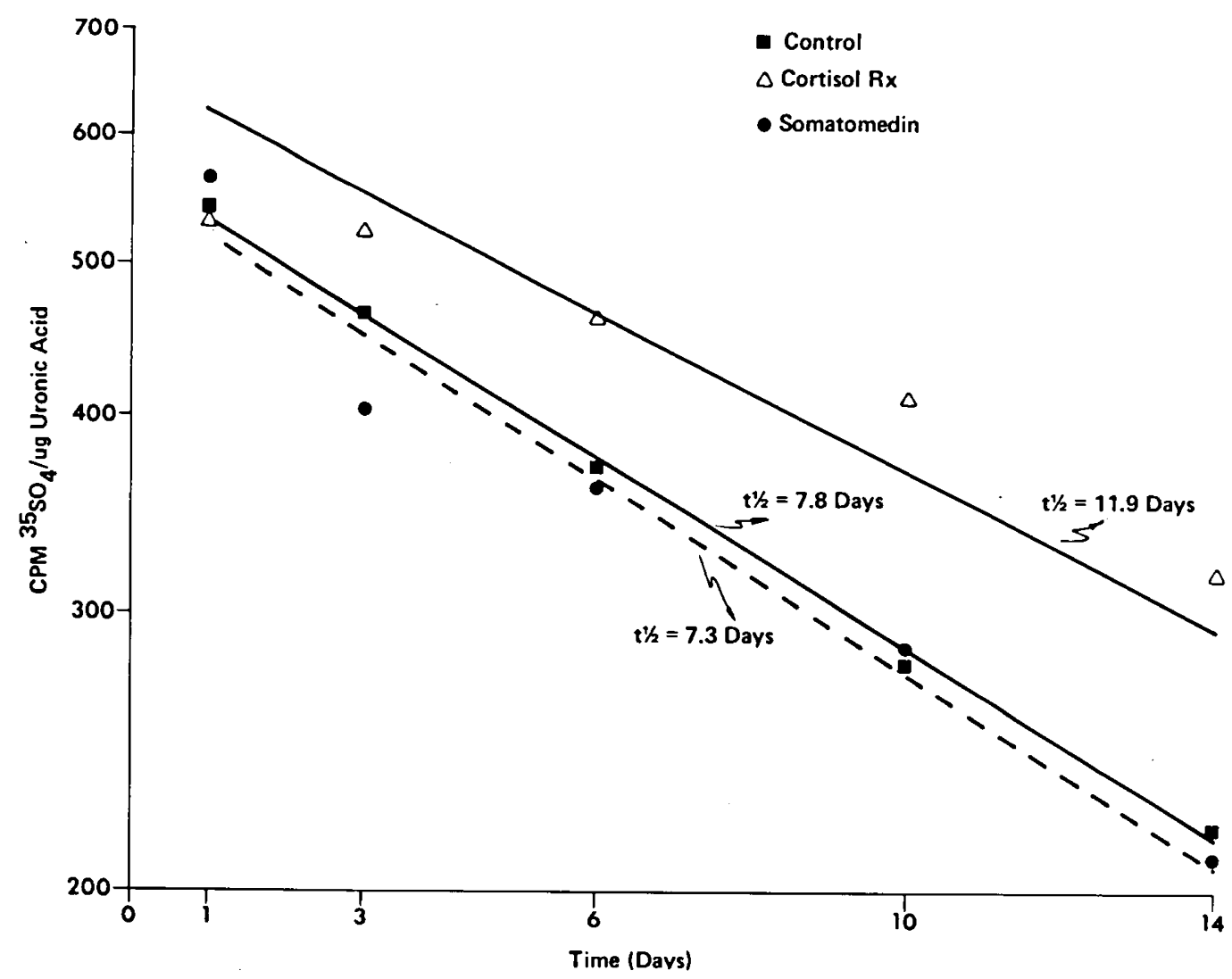

Fig. 3. Semilogarithmic plot of glycosaminoglycan turnover in control, cortisol-, and somatomedin-treated chick cartilage. Cartilage-sulfated glycosaminoglycans were prelabeled with ${ }^{35} \mathrm{~S}$ and the rate of disappearance estimated. The half-times for disappearance of the radiosulfate are as indicated. (Each point represents the mean for five pelvic rudiments.)

Table 1. Glycosyltransferase activities in control, cortisol-, and somatomedin-treated cartilage in vitro ${ }^{1}$

\begin{tabular}{lccc}
\hline & \multicolumn{3}{c}{$\begin{array}{c}{ }^{14} \mathrm{C} \text { Sugar incorporated } \\
\text { (pmole/mg protein/hr) }\end{array}$} \\
\cline { 2 - 4 } \multicolumn{1}{c}{ Enzyme assayed } & Control & Cortisol & Somatomedin \\
\hline Xylosyltransferase & $29.3 \pm 4.8$ & $19.1 \pm 3.6$ & $49.8 \pm 6.1$ \\
Galactosyltransferase & $60.7 \pm 9.2$ & $46.0 \pm 7.9$ & $89.1 \pm 8.1$ \\
Glucuronyltransferase & $18.2 \pm 3.6$ & $14.1 \pm 2.3$ & $22.6 \pm 4.1$ \\
\hline
\end{tabular}

${ }^{1}$ Pelvic and long bone rudiments from 20 dozen 12-day-old chick embryos were removed, randomly divided, and incubated either in nutrient mixture alone or with $1 \mathrm{mM}$ cortisol or somatomedin. After $16 \mathrm{hr}$ of incubation, cartilage was removed, washed, and homogenized in $0.2 \mathrm{M}$ sucrose, $0.05 \mathrm{M}$ Tris buffer $(\mathrm{pH} 7.0)$, and centrifuged at $10,000 \times \mathrm{g}$. Enzymes were assayed as described in Materials and Methods. The values represent the mean and SE for six assays using $100 \mu 1$ of the $10,000 \times g$ supernatant fraction. The variations in enzyme activity from preparation to preparation using this method is $\pm 12.2 \%$ but the intraassay variability was less than $5 \%$.

fractions by salt precipitation and centrifugation at $105,000 \times g$, as described by Stoolmiller et al. (19). These separated enzyme $(105,000 \times g$ supernatant $)$ or acceptor $(105,000 \times g$ pellet $)$ fractions were then used to study the xylosyltransferase activities.

The data presented in Table 2 show that xylose incorporation into acceptor protein, using the enzyme fraction from the control preparation with acceptor from control, cortisol and somatomedin preparations are $25.6,14.9$, and $44.2 \mathrm{pmole} / \mathrm{mg}$ protein $/ \mathrm{hr}$, respectively. When the enzyme fraction from the cortisol-treated group is used, the rate of xylose incorporated into acceptor from control, cortisol-, and somatomedin-treated cartilage is $21.6,12$, and $34 \mathrm{pmole} / \mathrm{mg} / \mathrm{hr}$, respectively. By using the somatomedintreated, enzyme fraction, the incorporation was 39,27 , and 58 $\mathrm{pmole} / \mathrm{mg}$ protein $/ \mathrm{hr}$, respectively. From these data it appears
Table 2. Xylosyltransferase activity of mixed fractions from control, cortisol-, and somatomedin-treated cartilage ${ }^{1}$

\begin{tabular}{lccc}
\hline & \multicolumn{3}{c}{$\begin{array}{c}\text { Xylose incorporated } \\
\text { protein } / \mathrm{hr} \text { ) }\end{array}$} \\
\cline { 2 - 4 } & \multicolumn{3}{c}{$105,000 \times g$ supernatant (Enzyme) } \\
\cline { 2 - 4 } $\begin{array}{c}105,000 \times g \text { pellet } \\
\quad \text { (acceptor) }\end{array}$ & Control & Cortisol & Somatomedin \\
\hline Control & $25.6 \pm 3.1$ & $21.6 \pm 2.1$ & $39.4 \pm 4.6$ \\
Cortisol & $14.9 \pm 1.6$ & $12.0 \pm 1.8$ & $27.0 \pm 2.3$ \\
Somatomedin & $44.2 \pm 3.8$ & $34.0 \pm 4.1$ & $57.7 \pm 4.9$ \\
\hline
\end{tabular}

${ }^{1}$ Pelvic rudiments and long bone cartilage from 20 dozen 12-day-old chick embryos were removed, randomly divided, and incubated for $16 \mathrm{hr}$ in nutrient mixture alone or with either $1 \mathrm{mM}$ cortisol or somatomedin. A $10,000 \times g$ supernatant solution was made $1 \mathrm{M} \mathrm{KCl}$, frozen and thawed six times, and centrifuged at $105,000 \times g$ for $1 \mathrm{hr}$. The resulting pellet (acceptor) was reconstituted with buffer to the same volume as the supernatant solution (enzyme). Fifty microliters of two fractions were mixed for the assay. The values are the mean for duplicate determinations in three separate assays.

that when acceptor fractions from cortisol-treated cartilage is used, the activities of all three enzyme preparations are decreased to 14 , 12 , and 27 , respectively, as compared with the control activities of 24,22 , and 39 , respectively. When acceptor from the somatomedin-treated cartilage is used, the activities of the three enzyme fractions are increased to 44,34 , and $58 \mathrm{pmole} / \mathrm{mg} / \mathrm{hr}$, respectively. These data suggest that endogenous acceptors are decreased in cortisol-treated cartilage and increased in somatomedin-treated cartilage as opposed to alterations in the enzyme.

To further distinguish between an effect on the enzyme and an effect on the acceptor, enzyme fractions from control, cortisol-, and somatomedin-treated cartilage were assayed using a Smithdegraded proteoglycan as an exogenous acceptor. Results are 
Table 3. Xylosyltransferase activity using endogenous and exogenous acceptor ${ }^{1}$

\begin{tabular}{lcc}
\hline & \multicolumn{2}{c}{ Xylose incorporated $(\mathrm{pmole} / \mathrm{mg}$ protein $/ \mathrm{hr})$} \\
\cline { 2 - 3 } $\begin{array}{c}\text { Enzyme } \\
\text { preparation }\end{array}$ & Endogenous acceptor & Exogenous acceptor \\
\hline Control & $29.2 \pm 3.4$ & $590 \pm 44.5$ \\
Cortisol & $16.4 \pm 1.4$ & $694 \pm 58.6$ \\
Somatomedin & $44.6 \pm 4.2$ & $688 \pm 52.1$ \\
\hline
\end{tabular}

' The enzyme and endogenous acceptor fractions were prepared as described for the experiment in Table 2. Smith-degraded proteoglycan $(250 \mu \mathrm{g})$ was added as exogenous acceptor with 5 nmole unlabeled UDPxylose. The values represent the mean $\pm S E$ for duplicate determinations in three separate assays.

shown in Table 3. The activity is again significantly higher in the somatomedin-treated cartilage and lower in the cortisol-treated cartilage when the $105,000 \times g$ pellet (endogenous acceptor) is the source of the acceptor. When a Smith-degraded proteoglycan is used as the exogenous acceptor, the enzyme activities from all three groups are almost identical. These results suggest that the activity of the enzyme, xylosyltransferase, is not rate limiting but the acceptor protein is decreased in cortisol-treated cartilage and increased in somatomedin-treated cartilage.

\section{DISCUSSION}

A partially purified factor obtained from boiled human serum was shown to stimulate sulfate uptake into embryonic chick cartilage. The rate was linear for $24 \mathrm{hr}$, and there was no effect on sulfate turnover by this somatomedin preparation. When embryonic chick cartilage was incubated in the presence of this factor, there was an increase in the activity of the enzymes involved in the synthesis of the glycosaminoglycans linkage region, especially xylosyltransferase. Cortisol has the opposite effect on this system as has been shown by in vivo studies (4).

Somatomedin has a number of documented effects on cartilage. These include stimulation of DNA, RNA, and protein synthesis $(17,18)$. Cortisol, both in vivo and in vitro inhibits these processes $(4,6)$. Two important proteins necessary for cartilage organization and growth are collagen and the acceptor protein for glycosaminoglycan (chondroitin sulfate) synthesis. The control of glycosaminoglycans synthesis appears to depend either on the rate of acceptor protein synthesis (14) or the rate of xylosylation of preformed acceptor by the enzyme, UDP xylosyltransferase (19).

When the enzyme and the endogenous acceptor from control, cortisol-, and somatomedin-treated cartilage were partially separated and assayed by mixing the various enzyme and acceptor fractions, it appeared that somatomedin increased and cortisol decreased both the amount of xylosyltransferase and the amount of endogenous acceptor. However, when excess exogenous acceptor was added to the enzyme fractions, there was no significant difference in the enzyme activities in the control, cortisol-, and somatomedin-treated cartilage.

The result of these experiments suggest that the primary action of somatomedin and cortisol on glycosaminoglycans biosynthesis is at the level of synthesis of the acceptor protein. This interpretation agrees with the earlier observations that protein synthesis is necessary for glycosaminoglycan biosynthesis $(14,20)$ and glucocorticoid hormones, which appear to decrease the amount of endogenous acceptor and also decrease glycosaminoglycan synthesis (4). These studies cannot be interpreted to demonstrate a specific site of action. The effect may be a general one with somatomedin increasing and cortisol decreasing the synthesis of many proteins within the cartilage cell.

The evidence suggests that growth hormone increases glycosaminoglycan content of growing cartilage (6) by increasing somatomedin production. This mediator increases the rate of syn- thesis of glycosaminoglycan acceptor protein with a subsequent increase in radiosulfate incorporation, content of sulfated glycosaminoglycans, and long bone growth. Cortisol, on the other hand, decreases the rate of synthesis of glycosaminoglycan acceptor protein, with a subsequent decrease in radiosulfate incorporation, content of sulfated glycosaminoglycans, and long bone growth.

\section{REFERENCES AND NOTES}

I. Baker, J. R., Roden, L., and Stoolmiller, A. C.: Biosynthesis of chondroitin sulfate proteoglycan. J. Biol. Chem., 247: 3838 (1972).

2. Bitter, T., and Muir, H. M.: A modified uronic acid carbazole reaction. Anal. Biochem., 4: 330 (1962)

3. Chochinov, R. H., Mariz, I. K., and Daughaday, W. H.: Isolation of a somatomedin from plasma of rats bearing growth hormone secreting tumors. Endocrinology, 100: 549 (1977).

4. Elders, M. J., McNatt, M. L., Kilgore, B. S., and Hughes, E. R.: Glucocorticoid inhibition of glycosaminoglycan biosynthesis: Decrease of protein acceptor. Biochem. Biophys. Res. Commun., 77: 557 (1977).

5. Elders, M. J., Smith, J. D., Smith, W. G., and Hughes, E. R.: Alterations in glycosaminoglycan metabolism in $\beta$-aminopropionitrile-treated chick embryos. Biochem. J., 136: 985 (1973).

6. Elders, M. J., Wingfield, B. S., McNatt, M. L., Lee, J. A., and Hughes, E. R.: Somatomedin and the regulation of skeletal growth. Ann. Clin. Lab. Sci., 5: 440 (1975).

7. Grebner, E. E., Hall, C. W., and Neufeld, E. F.: Incorporation of D-xylose-C ${ }^{14}$ into glycoprotein by particles from hen oviduct. Biochem. Biophys. Res. Commun., 22: 672 (1966).

8. Koumans, J., and Daughaday, W. H.: Amino acid requirements for activity of partially purified sulfation factor. Trans. Assoc. Am. Physician, 76: 152 (1963).

9. Kunin, A. S., and Meyer, W. L.: The effect of cortisone on the intermediary metabolism of epiphyseal cartilage from rats. Arch Biochem. Biophys., 129: 421 (1969).

10. Lam, C. N., and Arneil, G. C.: Long-term dwarfing effects of corticosteroid treatment for childhood nephrosis. Arch. Dis. Child., 43: 589 (1968).

11. Lindahl, U., and Roden, L.: The chondroitin 4-sulfate-protein linkage. J. Biol. Chem., 241: 2113 (1966)

12. Lowry, O. H., Rosebrough, N. J., Farr, A. L., and Randall, R. J.: Protein measurement with the Folin phenol reagent. J. Biol. Chem., 193: 265 (1951)

13. McNatt, M. L., Fiser, F. M., Elders, M. J., Kilgore, B. S., Smith, W. G., and Hughes, E. R.: Uridine diphosphate xylosyltransferase activity in cartilage from manganese-deficient chicks. Biochem. J., 160: 211 (1976).

14. Robinson, H. C., Brett, M. J., Tralaggan, P. J., Lowther, D. A., and Okayama, M.: The effect of $D$-xylose, $\beta$-D-xylosides and $\beta$-D-galactosides on chondroitin sulfate biosynthesis in embryonic chicken cartilage. Biochem. J., 148: 25 (1975)

15. Roden, L.: Biosynthesis of acidic glycosaminoglycans (mucopolysaccharides). In: W. H. Fisherman: Metabolic Conjugation and Metabolic Hydrolysis, Vol. 2. p 345 (Academic Press, NY, 1970).

16. Salmon, W.D., and Daughaday, W. H.: A hormonally controlled serum factor which stimulates sulfate incorporation by cartilage in vitro. J. Lab. Clin. Med. 49: 825 (1957)

17. Salmon, Jr., W. D., and DuVall, M. R.: A serum fraction with "sulfation factor activity" stimulates in vitro incorporation of leucine and sulfate into proteinpolysaccharide complexes, uridine into RNA, and thymidine into DNA of costal cartilage from hypophysectomized rats. Endocrinology, 86: 721 (1970).

18. Salmon, Jr., W. D., and DuVall, M. R.: In vitro stimulation of leucine incorporation into muscle and cartilage protein by a serum fraction with sulfation factor activity: Differentiation of effects from those of growth hormone and insulin. Endocrinology, 87: 1168 (1970).

19. Stoolmiller, A. C., Horwitz, A. L., and Dorfman, A.: Biosynthesis of the chondroitin sulfate proteoglycan. J. Biol. Chem., 247: 3525 (1972).

20. Telser, A., Robinson, H. C., and Dorfman, A.: The biosynthesis of chondroitinsulfate protein complex. Proc. Natl. Acad. Sci USA, 54: 912 (1965).

21. Keith Smith Hatchery, Hot Springs, AR.

22. Humidaire Incubator Co., New Madison, $\mathrm{OH}$

23. Grand Island Biological Co., Grand Island, NY.

24. Merck, Sharp and Dohme, West Point, PA.

25. UDP $\left[U \cdot{ }^{14} \mathrm{C}\right] x y$ lose $(172 \mathrm{Ci} / \mathrm{mole})$, New England Nuclear Corp., Boston, MA.

26. Sigma Chemical Company, St. Louis, MO.

27. PGSD was prepared by and kindly given to us by Dr. Nancy Schwartz. University of Chicago.

28. UDP [ $\left.U-{ }^{14} \mathrm{C}\right]$ galactose $(280 \mathrm{Ci} / \mathrm{mole})$, New England Nuclear Corp., Boston, MA.

29. UDP $\left[U_{-}{ }^{14} \mathrm{C}\right]$ glucuronic acid $(233 \mathrm{Ci} /$ mole $)$, New England Nuclear Corp., Boston, MA.

30. New England Nuclear Corporation, Boston, MA.

31. The studies at the University of Arkansas School for Medical Sciences were supported by USPHS Grants AM1590I and CA13907, Grant AM17550.

32. Requests for reprints should be addressed to: M. J. Elders, M.D. Department of Pediatrics, University of Arkansas for Medical Sciences, Little Rock. AR (USA).

33. Received for publication November 16, 1977

34. Accepted for publication March 21, 1978. 